\title{
Post-Traumatic Stress and Academic Performance Among Entry- Level Doctoral Physical Therapy Students in a Human Anatomy Cadaver Dissection Course
}

Sue E. Curfman

University of Lynchburg, curfman.s@lynchburg.edu

Gary P. Austin

University of Lynchburg, austin.g@lynchburg.edu

Joyce S. Nicholas

University of Lynchburg, nicholas_js@lynchburg.edu

Follow this and additional works at: https://nsuworks.nova.edu/ijahsp

Part of the Anatomy Commons, Mental and Social Health Commons, and the Physical Therapy Commons

\section{Recommended Citation}

Curfman SE, Austin GP, Nicholas JS. Post-Traumatic Stress and Academic Performance Among EntryLevel Doctoral Physical Therapy Students in a Human Anatomy Cadaver Dissection Course. The Internet Journal of Allied Health Sciences and Practice. 2018 Jan 01;16(3), Article 1.

This Manuscript is brought to you for free and open access by the College of Health Care Sciences at NSUWorks. It has been accepted for inclusion in Internet Journal of Allied Health Sciences and Practice by an authorized editor of NSUWorks. For more information, please contact nsuworks@nova.edu. 


\title{
Post-Traumatic Stress and Academic Performance Among Entry-Level Doctoral Physical Therapy Students in a Human Anatomy Cadaver Dissection Course
}

\begin{abstract}
Background: Dissection of human cadavers can be a stressful experience for students. Purpose: The purposes of this study were twofold: 1) to determine if physical therapy students develop or experience a worsening of post-traumatic stress disorder (PTSD) symptoms during exposure to and dissection of human cadavers; and 2) to determine if these symptoms are related to academic performance. Methods: Previous history of a diagnosis of anxiety or post-traumatic stress disorder and level of prior exposure to cadavers were recorded among 26 entry-level first semester doctoral students in physical therapy (DPT) taking gross human anatomy. Their level of anxiety about working with cadavers before and after the course was recorded. The Life Events Checklist (LEC-5) for Diagnostic and Statistical Manual of Mental Disorders, Fifth Edition (DSM-5) was used as a self-report measure to record potentially traumatic events in a subject's life prior to the study and during the course. Subjects also completed the Post-Traumatic Stress Disorder Checklist (PCL-5) at the beginning and end of the course to assess for symptoms of posttraumatic stress disorder. Student performance was assessed using written and practical examination grades. Results: Overall, the PCL-5 score for the group decreased significantly over the semester $(p=$ 0.01). However, 3 subjects' PCL-5 scores increased. Risk factors present among these subjects included previous diagnosis of post-traumatic stress disorder or anxiety, combat exposure, history of physical or sexual abuse, lack of previous exposure to cadavers, and coinciding traumatic events. Written examination performance was not significantly related to either change in PCL-5 $(p=0.84)$ or post-PCL-5 $(p=0.69)$ scores. Practical examination performance was not significantly related to either change in PCL-5 $(p=$ $0.28)$ or post-PCL-5 $(p=0.51)$ scores. However, consistent with previous research, students with a history of post-traumatic stress disorder and/or anxiety did have statistically significant lower written examination scores. Conclusions: Physical therapy students neither developed nor experienced a worsening of, but rather a reduction in, PTSD symptoms during exposure to and dissection of human cadavers. Overall, symptoms of PTSD did not seem to be related to academic performance.
\end{abstract}

\section{Author Bio(s)}

Sue E. Curfman, PT, DHSc is an associate professor in the Doctor of Physical Therapy Program, School of Graduate Studies at Lynchburg College in Lynchburg, Virginia. She teaches anatomy, kinesiology and orthopaedics.

Gary P. Austin, PT, PhD is a professor in the Doctor of Physical Therapy Program, School of Graduate Studies at Lynchburg College in Lynchburg, Virginia. He teaches orthopaedics, clinical inquiry, and differential diagnosis.

Joyce S. Nicholas, PhD is an associate professor and Director of Evaluation, Assessment, and Compliance for the Department of Physician Assistant Medicine, School of Graduate Studies at Lynchburg College in Lynchburg, Virginia. She teaches research methods and oversees thesis projects. 


\title{
IIIAHSP \\ The Internet Joưnal of Allied Health Sciences and Practice
}

Dedicated to allied health professional practice and education

Vol. 16 No. 3 ISSN 1540-580X

\section{Post-traumatic Stress and Academic Performance Among Entry-Level Doctoral Physical Therapy Students in a Human Anatomy Cadaver Dissection Course}

\author{
Sue E. Curfman, PT, DHSc \\ Gary P. Austin, PT, PhD \\ Joyce S. Nicholas, PhD \\ University of Lynchburg
}

United States

\begin{abstract}
Background: Dissection of human cadavers can be a stressful experience for students. Purpose: The purposes of this study were twofold: 1) to determine if physical therapy students develop or experience a worsening of post-traumatic stress disorder (PTSD) symptoms during exposure to and dissection of human cadavers; and 2) to determine if these symptoms are related to academic performance. Methods: Previous history of a diagnosis of anxiety or post-traumatic stress disorder and level of prior exposure to cadavers were recorded among 26 entry-level first semester doctoral students in physical therapy (DPT) taking gross human anatomy. Their level of anxiety about working with cadavers before and after the course was recorded. The Life Events Checklist (LEC-5) for Diagnostic and Statistical Manual of Mental Disorders, Fifth Edition (DSM-5) was used as a selfreport measure to record potentially traumatic events in a subject's life prior to the study and during the course. Subjects also completed the Post-Traumatic Stress Disorder Checklist (PCL-5) at the beginning and end of the course to assess for symptoms of post-traumatic stress disorder. Student performance was assessed using written and practical examination grades. Results: Overall, the PCL-5 score for the group decreased significantly over the semester $(p=0.01)$. However, 3 subjects' PCL-5 scores increased. Risk factors present among these subjects included previous diagnosis of post-traumatic stress disorder or anxiety, combat exposure, history of physical or sexual abuse, lack of previous exposure to cadavers, and coinciding traumatic events. Written examination performance was not significantly related to either change in PCL-5 $(p=0.84)$ or post-PCL-5 ( $p=0.69)$ scores. Practical examination performance was not significantly related to either change in PCL-5 $(p=0.28)$ or post-PCL-5 $(p=$ 0.51 ) scores. However, consistent with previous research, students with a history of post-traumatic stress disorder and/or anxiety did have statistically significant lower written examination scores. Conclusions: Physical therapy students neither developed nor experienced a worsening of, but rather a reduction in, PTSD symptoms during exposure to and dissection of human cadavers. Overall, symptoms of PTSD did not seem to be related to academic performance.
\end{abstract}

Key Words: anxiety, education, PCL-5, live events checklist 


\section{INTRODUCTION}

Human cadaver dissection is common practice in physical therapist education. It is well established that exposure to and dissection of human cadavers can be a stressful experience for students. ${ }^{1-7}$ Student concerns about working with human cadavers have been well documented. 3,6,8-12 Although the majority of students ultimately feel positive about the anatomy dissection experience, there remains a small percentage of students for whom the initial human cadaver dissection may be a difficult experience. $3,6,7,9-11,13$ While this response is well documented, it is not known if this distress rises to a level of clinically meaningful post-traumatic stress disorder (PTSD) or impacts academic performance.

There is some evidence to suggest that PTSD symptoms may be provoked by exposure to the human cadavers in an anatomy lab. ${ }^{14}$ Post-traumatic stress responses to human cadaver dissection have been documented, primarily in medical students. In a long-term observational study of medical students in a human anatomy dissection course, Finkelstein and Mathers found a high prevalence of symptoms suggestive of post-traumatic stress disorder (PTSD). ${ }^{14}$ However, the lack of both objective clinical measurements of PTSD symptoms and reports of previous exposure to traumatic events limit the interpretation of these findings.

PTSD has typically been considered to develop following traumatic events. A traumatic event is now defined as one in which an individual either directly experiences or witnesses, in person, an event involving actual death, threatened death, actual or threatened serious injury, or sexual violence. ${ }^{15}$ In addition, learning that a close friend or relative was involved in a violent or accidental event, as well as repeated exposure to details of aversive events qualifies for diagnosis. ${ }^{15}$ There is also evidence that events not typically considered traumatic, instead life events may trigger PTSD symptoms. ${ }^{16}$

The National Center for PTSD reports that 7 to $8 \%$ of the population will develop PTSD in their lifetime. ${ }^{17-20}$ More recent estimates using the Diagnostic and Statistical Manual of Mental Disorders, Fifth Edition (DSM-5) criteria report a lifetime prevalence of $16 \% .{ }^{20}$ Among college students, the prevalence is reported to be 8 to $9 \% .{ }^{19} \mathrm{It}$ is, therefore, probable that a number of students entering graduate physical therapy programs have a history of trauma and may have been diagnosed with PTSD prior to matriculation.

Signs and symptoms of PTSD can include anxiety, disturbing dreams about traumatic events, a state of hyperalertness or feeling easily startled, irritability, sleep disturbance, trouble remembering important information about traumatic events, depression, and difficulty concentrating among other things. ${ }^{21,22}$ Adverse emotional responses such as fear, depression, recurring visual images of cadavers, insomnia, palpitation, loss of appetite, and more frequent thoughts about death and dying have all been reported among students working with human cadavers. $7,12,13,23-27$

PTSD and anxiety have been associated with general learning and memory impairments. ${ }^{28-32}$ Developing or experiencing a worsening of PTSD may increase the risk of students failing in a physical therapy curriculum. Additionally, the following have been identified as factors that may increase the risk of developing PTSD: female gender, genetic factors, physiologic factors, history of childhood sexual abuse, and/or history of physical abuse. ${ }^{33-35}$ The ability to identify at risk students and to subsequently provide helpful resources may enhance student learning and performance, ultimately improving retention in the program.

The purposes of this study were twofold: 1) to determine if physical therapy students develop or experience a worsening of PTSD symptoms during exposure to and dissection of human cadavers, and 2) to determine if these symptoms are related to academic performance.

\section{METHODS}

All entry-level first year doctoral physical therapy students enrolled in a 10-week, six credit graduate level Gross Human Anatomy course were invited to voluntarily participate in this study by an introductory email with one follow-up reminder invitation. Interested students attended a meeting with support staff from the DPT program who read an introductory script and offered consent forms. Thirty-two of 50 students consented to participate and 26 completed all data collection forms. Three students failed to complete all initial forms. Three students failed to complete all final forms. Consequently, $64 \%$ of the class consented to participate and $19 \%$ of this group did not complete the study. Subjects were recruited in the days prior to their arrival on campus for orientation to the program and invited to attend a meeting on the first day of class.

On the first day of class, subjects completed an online general intake form providing the following demographic and historical information: gender, age, previous experiences with human cadavers, and history of being diagnosed with or treated for PTSD or anxiety disorders (Table 1). Subjects also responded to a single question asking them to rate their current level of anxiety about

(C) The Internet Journal of Allied Health Sciences and Practice, 2018 
working with cadavers on a 5-point Likert scale with 0 being "not anxious at all" and 5 being "severely anxious". This same question was repeated at the end of the study.

Table 1: Descriptive Statistics

\begin{tabular}{|l|c|}
\hline Baseline Characteristics of Subjects & \\
\hline Mean age & $23.2(20$ to 37$)$ years \\
\hline Male & $35 \%(9 / 26)$ \\
\hline No previous exposure to a human cadaver & $46 \%(12 / 26)$ \\
\hline Worked with human cadaver prosections & $46 \%(12 / 26)$ \\
\hline Performed human cadaver dissection & $8 \%(2 / 26)$ \\
\hline $\begin{array}{l}\text { Previous diagnosis of PTSD and anxiety } \\
\text { Treated with counseling and medication prior to the study } \\
\quad \text { No treatment during the course of the study }\end{array}$ & $4 \%(1 / 26)$ \\
\hline $\begin{array}{l}\text { Previous diagnosis of anxiety disorder } \\
1 / 8 \text { treated with medication prior to the study } \\
1 / 8 \text { treated with medications and counseling prior to the study } \\
6 / 8 \text { treated with counseling prior to the study } \\
0 / 8 \text { being treated during the course of the study }\end{array}$ & $35 \%(8 / 26)$ \\
\hline
\end{tabular}

Subjects completed two other online surveys at the beginning and end of the 10-week course. Both surveys are associated with the Diagnostic and Statistical Manual of Mental Disorders, Fifth Edition (DSM-5). To assess previous exposure to traumatic events, subjects completed a Life Events Checklist (LEC-5) for the DSM-5, which is a self-report measure designed to screen for potentially traumatic events in a respondent's lifetime. The LEC- 5 was developed at the National Center for Posttraumatic Stress Disorder and is widely used in the clinical and research contexts. ${ }^{38}$ The LEC-5 assesses exposure to 16 events known to potentially result in PTSD or distress and includes one additional item assessing any other extraordinarily stressful event not captured in the first 16 items. Examples of traumatic events included on the LEC-5 are natural disasters, motor vehicle accidents, physical assault, sexual assault, combat, life-threatening illness, violent behavior, sudden violent death, etc. (See appendix 1 for full list of events included LEC-5)

The LEC- 5 asks subjects to report if: a) traumatic events happened to them personally; $b$ ) they witnessed traumatic events happen to someone else; $c$ ) they learned about them happening to a close family member or close friend; d) they were exposed to traumatic events as part of their job (e.g., paramedic, police, military, or other first responder); e) they are not sure if it fits; or f) traumatic type events do not apply to them. At the beginning of the course, subjects were instructed to consider their entire lives when completing the form while only considering events which occurred during the course for the post-course form. Total scores from pre-course LEC-5 were calculated to assess exposure to traumatic events prior to the course. Exposure to traumatic events over the duration of the course was noted from post-course LEC- 5 scores.

Lastly, subjects completed the PTSD Checklist for DSM-5 (PCL-5) at the beginning and end of the course. ${ }^{39}$ The PCL is the most widely used self-report measure of PTSD in both research and clinical contexts. ${ }^{40,41}$ The PCL-5 is a 20 -item self-report measure that assesses for symptoms of PTSD reported in the DSM-5. The PCL-5 uses a 5-point Likert scale where 0 is "Not at all" and 4 is "Extremely" and the ratings are summed to provide a symptom severity score ranging from $0-80$. The PCL-5 at the beginning of the course asked subjects about symptoms they had been experiencing during the previous month. PCL-5 at the end of the course asked subjects about symptoms they had experienced over the 10-week course.

The PCL-5 has a variety of uses, including: monitoring symptom change during and after treatment, screening individuals for PTSD, and making a provisional PTSD diagnosis. ${ }^{39}$ Over the years, the cutoff score for diagnosing PTSD using older versions of the PCL has been reported by numerous authors to range between 31 - 34 out of $80.42-46$ The cutoff score of 31 was used in this

(c) The Internet Journal of Allied Health Sciences and Practice, 2018 
study as this is the cutoff score reported by Ashbaugh using the updated DSM-5 diagnostic guidelines to the PCL-5. ${ }^{47}$ The National Center for PTSD recommends using 5 points as the minimal detectable change (MDC) for determining whether an individual has responded to treatment and 10 points as the minimal clinically important difference (MCID) threshold using the PCL for DSM-IV. ${ }^{17,46}$ Change scores for PCL-5 are currently being determined and it is expected that reliable and clinically meaningful change will be in a similar range. ${ }^{17}$

A provisional PTSD diagnosis can also be made by analyzing the PCL results according to clusters. The PCL-5 examines four clusters (B-E) each signifying different issues; positive cluster B (items $1-5$ ) indicates the traumatic event is persistently reexperienced; positive cluster $\mathrm{C}$ (items 6-7) indicates avoidance of trauma-related stimuli after the trauma; positive cluster D (items 8-14) indicates negative thoughts or feelings that began or worsened after the trauma; and positive cluster $E$ (items 15-20) indicates trauma-related arousal and reactivity that began or worsened after the trauma. A provisional PTSD diagnosis can be made if one $B$, one $C$, two $D$, and two $E$ cluster items are positive as indicated by a rating of moderate on those items. ${ }^{44,45}$

As a measure of student performance, at the end of the semester, faculty from the course provided written and practical examination grades for all subjects.

\section{Data Analysis}

In the same manner that it is used clinically, the PCL-5 data was used to analyze symptoms and identify PTSD. Changes in PTSD symptoms were examined by analyzing the overall PCL score before and after the course using the Wilcoxon Signed Ranks Test. Subjects were observed for who may have had either sufficient symptoms to indicate a newly identified provisional diagnosis of PTSD or worsening of known PTSD over the course of the study using the PCL-5 cutoff score of 31 and cluster analysis of PCL- 5 data using the DSM- 5 criteria for PTSD. Correlations between exam grades and PTSD symptoms using the overall post-PCL-5 scores and change in PCL-5 scores were analyzed using non-parametric Spearman's rho correlation. Differences in exam scores between students with PTSD and those without PTSD were analyzed using a 2-sided independent samples t-test. Various correlations between grades and other factors (e.g., trauma exposure) were considered. Anxiety level related to working with cadavers was analyzed comparing pre/post responses to a single question using Wilcoxon Signed Ranks Test. Differences between reported anxiety levels among subjects with various levels of exposure to cadavers prior to the course were analyzed using the Kruskal Wallis for nonparametric data.

\section{RESULTS}

Table 2 details the subjects' exposure to traumatic events prior to and during the course. Three subjects reported that a traumatic event happened to them during the study; one was a serious accident at work, home, or during recreational activity and two were unspecified very stressful events or experiences. One of these subjects was newly diagnosed with anxiety and treated with medication and counseling over the semester.

Rates of personal exposure to traumatic events experienced prior to the study and during the study according to the Life Events Checklist (LEC-5). 17/26 of subjects reported at least one traumatic event happened to them prior to the study. The sum of the numbers exceeds 17 because some subjects experience more than 1 traumatic event prior to the study. One of these subjects was newly diagnosed with anxiety and treated with medication and counseling during the course.

Overall, the median PCL-5 score for the group decreased over the semester from 12.5 (range $=0$ to 37 ) to 3 (range $=0$ to 41 ) indicating a reduction in PTSD symptoms $(p=0.01)$. See table 3 for PCL- 5 data by subjects. There were no subjects newly diagnosed with PTSD by an external health care provider during the course, but one subject who was previously diagnosed with anxiety and PTSD but was not symptomatic at the beginning of the study met the criteria for a provisional diagnosis of PTSD at the end of the course with a post-PCL-5 score of 41 and positive cluster analysis. Two subjects missed meeting the criteria for a provisional diagnosis of PTSD because they were missing a cluster $C$ item (avoidance). See table 4 for data on subjects diagnosed with PTSD throughout this study. Eleven subjects reported experiencing some symptoms of PTSD during the course. See table 5 for more detailed information about the nature and frequency of symptoms experienced. There were significant correlations between post-PCL-5 scores and self-reported pre-anxiety score $(R=-0.39, p=0.049)$ and self-reported post-anxiety scores $(R=.53, p=.005)$.

(c) The Internet Journal of Allied Health Sciences and Practice, 2018 
Table 2: Rates of Personal Exposure to Traumatic Events

\begin{tabular}{|l|c|c|}
\hline Type of Traumatic Event & $\begin{array}{c}\text { Prior to } \\
\text { study }\end{array}$ & $\begin{array}{c}\text { During } \\
\text { study }\end{array}$ \\
\hline $\begin{array}{l}\text { Natural disaster (for example, flood, hurricane, tornado, } \\
\text { earthquake) }\end{array}$ & $10 / 26$ & - \\
\hline Fire or explosion & $1 / 26$ & - \\
\hline $\begin{array}{l}\text { Transportation accident (for example, car accident, boat } \\
\text { accident, train wreck, plane crash) }\end{array}$ & $7 / 26$ & - \\
\hline $\begin{array}{l}\text { Serious accident at work, home, or during recreational } \\
\text { activity }\end{array}$ & $3 / 26$ & $1 / 26$ \\
\hline $\begin{array}{l}\text { Exposure to toxic substance (for example, dangerous } \\
\text { chemicals, radiation) }\end{array}$ & - & - \\
\hline $\begin{array}{l}\text { Physical assault (for example, being attacked, hit, } \\
\text { slapped, kicked, beaten up) }\end{array}$ & $2 / 26$ & - \\
\hline $\begin{array}{l}\text { Assault with a weapon (for example, being shot, stabbed, } \\
\text { threatened with a knife, gun, bomb) }\end{array}$ & $1 / 26$ & - \\
\hline $\begin{array}{l}\text { Sexual assault (rape, attempted rape, made to perform } \\
\text { any type of sexual act through force or threat of harm) }\end{array}$ & $3 / 26$ & - \\
\hline $\begin{array}{l}\text { Other unwanted or uncomfortable sexual experience } \\
\text { Any other very stressful event or experience }\end{array}$ & $2 / 26$ & - \\
\hline $\begin{array}{l}\text { Combat or exposure to a war-zone (in the military or as a } \\
\text { civilian) }\end{array}$ & $1 / 26$ & - \\
\hline $\begin{array}{l}\text { Captivity (for example, being kidnapped, abducted, held } \\
\text { hostage, prisoner of war) }\end{array}$ & - & - \\
\hline $\begin{array}{l}\text { Life threatening illness or injury } \\
\text { else }\end{array}$ & $2 / 26$ & - \\
\hline Severe human suffering & - & - \\
\hline Sudden violent death (for example, homicide, suicide) & - & - \\
\hline Sudden accidental death & $-26{ }^{*}$ \\
\hline Serious injury, harm, or death you caused to someone & - \\
\hline
\end{tabular}


Table 3: Historical Data of Subjects who Experienced Significant Change in PCL-5 Score ( $\geq 10 \mathrm{MCID}$ ) During the Study

\begin{tabular}{|l|c|c|c|}
\hline Historical Data & $\begin{array}{l}\text { Total } \\
\text { subjects }\end{array}$ & $\begin{array}{l}\text { Subjects } \\
\text { with } \\
\text { Increased } \\
\text { PCL-5 } \\
\text { Score }\end{array}$ & $\begin{array}{l}\text { Subjects with } \\
\text { Decreased PCL- } \\
\text { 5 Score }\end{array}$ \\
\hline Significant change PCL-5 score & $15 / 26$ & $3 / 15$ & $12 / 15$ \\
\hline History of PTSD and or anxiety disorder & $9 / 26$ & $2 / 3$ & $4 / 12$ \\
\hline History of sexual trauma & $3 / 26$ & $1 / 3$ & $1 / 12$ \\
\hline History of physical assault & $2 / 26$ & $1 / 3$ & $0 / 12$ \\
\hline History of military service & $1 / 26$ & $0 / 3$ & $1 / 12$ \\
\hline $\begin{array}{l}\text { Experienced trauma unrelated to the course } \\
\text { during the study }\end{array}$ & $2 / 26$ & $1 / 3$ & $2 / 12$ \\
\hline $\begin{array}{l}\text { Previous human cadaver dissection } \\
\text { experience }\end{array}$ & $2 / 26$ & $0 / 3$ & $2 / 12$ \\
\hline Previously observed human cadaver & $12 / 26$ & $2 / 3$ & $4 / 12$ \\
\hline No previous exposure to human cadavers & $12 / 26$ & $1 / 3$ & $6 / 12$ \\
\hline
\end{tabular}

Table 4: PTSD Diagnostic Data by Subject

\begin{tabular}{|c|c|c|c|c|}
\hline Subject identifier & $\begin{array}{l}\text { Diagnosed with } \\
\text { PTSD prior to study }\end{array}$ & $\begin{array}{l}\text { Diagnosed with } \\
\text { PTSD at end of } \\
\text { study }\end{array}$ & $\begin{array}{l}\text { History of } \\
\text { anxiety }\end{array}$ & $\begin{array}{l}\text { New diagnosis of } \\
\text { anxiety during } \\
\text { study }\end{array}$ \\
\hline $\mathrm{A}$ 우 & $\begin{array}{r}\text { (Cluster } \\
\text { analysis) }\end{array}$ & - & - & - \\
\hline $\mathrm{B} q$ & $\begin{array}{r}\quad \begin{array}{c}\text { (Cluster } \\
\text { analysis) }\end{array}\end{array}$ & - & - & - \\
\hline C $\hat{\sigma}$ & $+\quad$ (Cutoff score) & - & + & - \\
\hline D $\widehat{O}$ & $\begin{array}{c}\text { (Cluster } \\
\text { analysis and } \\
\text { cutoff score) }\end{array}$ & - & - & + \\
\hline $\mathrm{E} q$ & $+(\text { External })^{*}$ & $\begin{array}{l}+\quad \text { (Cluster } \\
\text { analysis and } \\
\text { cutoff score) }\end{array}$ & + & - \\
\hline $\mathrm{F} \delta$ & - & $\begin{array}{c}\sim+3 / 4 \text { cluster } \\
\text { items }\end{array}$ & + & - \\
\hline $\mathrm{G} \curvearrowright$ & - & $\begin{array}{c}\sim+3 / 4 \text { cluster } \\
\text { items }\end{array}$ & - & - \\
\hline
\end{tabular}


PTSD Diagnostic Data by Subject: The diagnostic criteria met for a provisional diagnosis of PTSD is indicated in () as either a PCL-5 cutoff score $\geq 31$ or + cluster analysis of PCL- 5 data. This subject had been diagnosed with PTSD and anxiety disorder by an external healthcare provider prior to the study. These subjects met 3 of 4 of the diagnostic criteria for PTSD according to cluster analysis. The missing criterion was avoidance behaviors possibly related to this course being required.

Table 5: Frequency of Subjects Experiencing PTSD Symptoms According to the Cluster Analysis of PCL-5 Data

\begin{tabular}{|l|c|c|c|c|}
\hline & $\begin{array}{c}\text { Re- } \\
\text { experiencing }\end{array}$ & $\begin{array}{c}\text { Avoidance } \\
\text { Behaviors }\end{array}$ & $\begin{array}{c}\text { Negative Thoughts } \\
\text { and Feelings }\end{array}$ & $\begin{array}{c}\text { Arousal and } \\
\text { Reactivity }\end{array}$ \\
\hline $\begin{array}{l}\text { 1 month prior to } \\
\text { course }\end{array}$ & $13 / 26(50 \%)$ & $9 / 26(35 \%)$ & $11 / 26(42 \%)$ & $14 / 26(54 \%)$ \\
\hline During course & $5 / 26(19 \%)$ & $2 / 26(8 \%)$ & $6 / 26(23 \%)$ & $8 / 26(31 \%)$ \\
\hline
\end{tabular}

There was a statistically significant difference in self-reported anxiety about working with cadavers among students with different levels of exposure to cadavers at the beginning of the course $(p=0.038)$, but not a statistically significant difference among students with various levels of exposure at the end of the course $(p=0.73)$. The median self-reported anxiety about working with a human cadaver at the beginning of the study was greater for students who had not observed a cadaver (median $=3.0$; range $=$ 2 to 5 ) than those who had previously worked with prosected cadavers or observed dissection (median $=2.0$; range $=1$ to 4 ) and those who previously dissected a human cadaver (median $=1.5$; range $=1$ to 2$)$. There was a statistically significant decrease $(p$ $=0.001$ ) in the median self-reported level of anxiety about working with human cadavers among all students over the course of the study from 2.0 (range $=1$ to 5 ) to 1 (range $=1$ to 3 ). No between group differences remained.

Written examination performance was not significantly related to either change in PCL-5 from pre- to post-course or post-PCL-5 scores ( $p=0.84$ and $p=0.69$, respectively). Practical examination performance was not significantly related to either change in PCL-5 from pre- to post-course or post-PCL-5 scores $(p=0.28$ and $p=0.51$, respectively). PCL- 5 change scores were analyzed to account for subjects with baseline PTSD symptoms.

\section{DISCUSSION}

In this study, the impact of working with human cadavers on symptoms and diagnosis of PTSD and subsequent academic performance was examined. The sample appears representative of our target population though some discussion is warranted. Life Events Checklist (LEC-5) results indicated that $65.4 \%$ (17/26) of the subjects reported at least one traumatic event happened to them prior to the course. This is consistent with expected levels of exposure to traumatic events for adults. The rates of exposure to traumatic events reported in the literature are variable. $17,19,20,48-50$ This variability is related to varying definitions of traumatic events on the instruments used to collect the data. In a national sample, researchers recently reported that over $80 \%$ of adults have been exposed to at least one traumatic event.20,47 Rates of reported exposure to traumatic events among college students range between 40-85\%,19,51,52 The mean overall pre-PCL-5 score among our subjects was more than 8 points lower with a substantially lower range than previously reported normative data in a nonclinical population.

Compared to Ashbaugh et al, our sample was older, consisted of fewer females, and had a higher percentage of participants holding bachelor's degrees. ${ }^{47} \mathrm{It}$ is possible that the differences in socioeconomic status, age, and gender between these two populations may account for the difference in mean PCL-5 scores. Lower socioeconomic status, younger age, and female sex have been shown to lower levels of distress tolerance and increase risk for PTSD. 53,54 .

To our knowledge, this study is the first to report point of entry PCL-5 scores among graduate students in a professional program. The prevalence of subjects diagnosed with PTSD prior to the study is less than half that reported among college students. ${ }^{19} \mathrm{It}$ is unclear whether this is representative of the class since it is unknown whether subjects with mental health issues are more or less likely to consent to participate in studies related to mental health. The prevalence of subjects who had previous exposure to cadavers in our study may appear high but is slightly less than the prevalence reported for physical therapy and medical students. ${ }^{55,56}$

The rate of reported anxiety disorders among our sample was nearly double that reported in the American adult population by the Anxiety and Depression Association of America. ${ }^{57}$ However, studies among medical students and age-matched peers

(C) The Internet Journal of Allied Health Sciences and Practice, 2018 
suggest higher prevalence of depression and anxiety among medical students. ${ }^{58}$ The 2016 American College Health Association-National College Health Assessment data indicates that many graduate and professional students suffer from a variety of mental health conditions. ${ }^{59}$ Survey questions regarding the previous 12-months indicated prevalence of overwhelming anxiety (55\%), overwhelming anger (33\%), depression that limited function (33\%), and thoughts of suicide (6\%). ${ }^{59}$

The overall PCL-5 scores demonstrated a statistically significant reduction over the course of the semester, suggesting an overall reduction in symptoms of PTSD during the study. Twelve subjects had a statistically significant reduction in PTSD symptoms during the study. The proportion of subject experiencing PTSD symptoms in the month prior to the study was unexpected (Table 5) and may represent the stress of preparing to enter a graduate professional program, relocating, and changing social and relational roles. Subjects were in their first semester of study so the decrease in PCL-5 scores may reflect habituation to the demands of graduate school, adjustments to relocation, and/or changing social and relational roles. However, there is the potential for subjects to experience a worsening of symptoms due to exposure to human cadaver dissection.

Three subjects experienced a clinically meaningful increase in PTSD symptoms. It is interesting to note that two of these subjects had been diagnosed with anxiety and/or PTSD prior to the study. Of the five subjects who had a diagnosis of, or met the diagnostic criteria for PTSD at the beginning of the study, one developed a worsening of symptoms. The subject who demonstrated a worsening of symptoms during the study reported a previous diagnosis of PTSD and reported three previously identified risk factors for PTSD: female, history of physical abuse, and history of sexual abuse. ${ }^{33,35}$ The other four subjects who met the established diagnostic criteria (1 based on cutoff PCL-5 score, 2 by cluster analysis, 1 met both criteria) for PTSD on the PCL-5 at the beginning of the study demonstrated a subsequent decrease in symptoms during the study. Although four of the subjects met the diagnostic criteria for PTSD at the beginning of the study, none of those four subjects met the diagnostic criteria for PTSD at the end of the study. This may reflect symptomatology related to the adjustment stress of graduate school as three of these four subjects had neither been diagnosed nor been treated for PTSD and/or anxiety prior to the study.

Subjects not diagnosed with PTSD at the beginning of the study have the potential to develop PTSD due to exposure to human cadaver dissection. ${ }^{14}$ Two subjects who neither had a diagnosis of, nor met the criteria for PTSD at the beginning of the study did meet three of the four diagnostic criteria for PTSD at the end of the study. The criteria these subjects didn't meet was cluster C, avoidance behaviors. This may be related to the course being a requirement, so students were unable to avoid exposure to and dissection of human cadavers. In addition, avoidance behaviors are behaviors subjects may display after being exposed to trauma. One of these subjects did report an unspecified very stressful event or experience on the post-LEC; the increase in PTSD symptoms may be related to this event during the study and not the exposure to cadavers. The other subject reported a history of an anxiety disorder. A larger sample size and control group in future studies may allow for more precise estimates of risk and elucidate this potentially important finding. Considering these two subjects and the subject who had a previous diagnosis of PTSD who experienced a worsening of PTSD symptoms during the study, our prevalence rate of PTSD was only slightly higher than the prevalence reported among college students. ${ }^{19}$

Although an overall decrease in symptoms was demonstrated, a small subset of subjects reported a worsening of symptoms. Potential risk factors for worsening may include previous diagnosis of anxiety, lack of previous exposure to human cadavers, and coinciding traumatic events. Despite overall reduction in symptoms, there appears to be a legitimate need to monitor all students for potential worsening. Additionally, all subjects who experienced a clinically meaningful increase in PTSD symptoms during the study had a history of military service or of sexual and physical abuse, consistent with the literature related to risk factors for PTSD. 33,35 Further research should consider the potential relationships between these risk factors and the potential for development of symptoms of PTSD.

Academic performance in the course was neither related to nor affected by changes in PTSD symptoms during exposure to and dissection of human cadavers. We explored for relationships between academic performance and PCL- 5 change scores to account for the potential effects of PTSD symptoms related to exposure to traumatic events prior to the study. Performance on written and practical examinations was not related to either the change in or the final PTSD symptoms. It was not expected for academic performance to be unrelated to or unaffected by changes in PTSD symptoms, however, the students generally performed well in the course. Several factors, such as the small sample size and the low number of participants with significant PTSD symptoms may have impacted this result.

Instead of exploring the results of PTSD symptoms on academic performance as indicated by exam scores, it may have been more meaningful to explore the impact of PTSD symptoms on clinical performance. Performance on written and practical examinations may be less susceptible to the negative influences of emotional distress. Measures of social and emotional

(C) The Internet Journal of Allied Health Sciences and Practice, 2018 
intelligence and assessments of interactions in the clinical setting may reflect the impact of PTSD symptoms on learning more so than exam scores. Students with suboptimal social and emotional skills are screened out during the admissions process which may have also impacted the results. Previous exposure to traumatic events was also unrelated to written or practical examination grades so it does not appear as though previous exposure to traumatic events influenced performance in the course. However, consistent with previous research, students with a history of PTSD and/or anxiety did have statistically significant lower written examination scores. $28,32,60$ Although students with a history of PTSD and/or anxiety demonstrated a significantly lower mean written examination score, the overall mean written examination score exceeded the minimum standards for success. However, unlike stronger students, marginal students with anxiety may be at increased risk for academic issues due to written examination performance. ${ }^{29,61,62}$

Three subjects reporting concurrent unrelated traumatic events during the study raises interesting points for discussion. One of the subjects who reported a very stressful event or experience during the study was also newly diagnosed with and treated for anxiety over the course of the semester. This subject had likely been exposed to more traumatic events than most other subjects prior to and during the study. The other subject who reported a very stressful event or experience during the study experienced a reliable and clinically significant increase in the PCL-5 score whereas the previously mentioned subject may not have had an increase in PCL-5 score because of the medical and psychological treatment received. Clinical interventions for PTSD have been shown to reduce related symptoms. ${ }^{63-66}$ However, the subject who reported a serious accident at work, home, or during recreational activity during the study had a PCL-5 score of 0 both prior to the study and at the end of the study, so had no PTSD symptoms prior to or during the study. This is consistent with the known fact that not all subjects develop PTSD symptoms following trauma. ${ }^{67}$

\section{Limitations}

Limitations of the study should be noted. Participation may have been improved if subjects were recruited after they arrived on campus and established working relationships with faculty. The email invitation sent to students to invite them to participate and the email with follow-up surveys sent to subjects listed separate links for each of the forms used in the study. This may have led to confusion and contributed to the dropout rate. Providing a single link with access to all of the forms may have reduced the dropout rate. Respondent fatigue when using long surveys and increased dropout rates with web-based surveys have also been reported in the literature. ${ }^{36,37}$ Selection bias may have been introduced as it is possible that stress avoidant students may have been less likely to volunteer to participate in this study. This may have been especially true as this study was initiated during the first day of class during their first course in the program, a time when many students are anxious about the expectations of graduate school. It is also possible that the lack of anonymity of one of the researchers, also a faculty member in this course, altered candid reporting of the effects of exposure to the cadaver lab.

The results of this study, coupled with previous findings suggest a potential need for educators to consider the history of anxiety and PTSD. Screening for a history of anxiety may be more important as this was related to academic performance. Screening for a history of previous diagnosis of PTSD may be indicated considering the subject in this study who had a previous history of PTSD and developed a worsening of symptoms. Additionally, educators may consider providing the opportunity for students to report coinciding traumatic events to faculty as 2 of the 3 students who reported traumatic events over the course of the study did experience an increase in PTSD symptoms. However, the limited number of subjects in this study with a history of PTSD limits the strength of this recommendation. Future research should examine the potential influence of anxiety and PTSD on student academic and clinical performance and retention throughout the curriculum. To enhance student success and well-being, educators should consider monitoring for history of anxiety and PTSD as well as coinciding traumatic events during exposure to and dissection of human cadavers.

\section{CONCLUSION}

Physical therapy students neither developed nor experienced a worsening of, but rather a reduction in, PTSD symptoms during exposure to and dissection of human cadavers. Overall, symptoms of PTSD did not seem to be related to academic performance.

(c) The Internet Journal of Allied Health Sciences and Practice, 2018 


\section{REFERENCES:}

1. Lamdin R, Weller J, Kerse N. Orientation to dissection: assisting students through the transition. Clin Anat. 2012;25(2):235-40. doi: 10.1002/ca.21244 [PMID: 21815220]

2. Böckers A, Baader C, Fassnacht UK, Ochsner W, Böckers TM. Reduction of mental distress in the dissection course by introducing the body donor experience through anatomical demonstrations of organ systems. Anat Sci Educ. 2012;5(6):321-9. doi: 10. 1002/ase. 1292 [PMID: 22653802]

3. Dubhashi, S, Dubhashi U, Singh A, Trinath T. Medical students react to cadaveric dissections. Recent Research Sci Tech. 2011;3(1):135-8.

4. Izunya AM, Oaikhena GA, Nwaopara AO. Attitudes to cadaver dissection in a Nigerian medical school. Asian J Med Sci. 2010;2(3):89-94. doi: 10.9790/0853-14527478

5. Cahill KC, Ettarh RR. Attitudes to anatomy dissection in an Irish medical school. Clin Anat. 2009;22(3):386-91. doi: 10. 1002/ca.20777. [PMID: 19280654]

6. Quince TA, Barclay SIG, Spear M, Parker RA, Wood DF. Student attitudes toward cadaveric dissection at a UK medical school. Anat Sci Educ. 2011;4(4):200-7. doi: 10.1002/ase.237. [PMID: 21656918]

7. Kumar VV, Lucas MA, Kumar V, Kulal P. Attitude of First Year Indian Medical Students Towards Cadaver Dissection. 2015. Accessed at: http://imsear.li.mahidol.ac.th/handle/123456789/174901. Date accessed: July 8, 2017.

8. Dosani F, Neuberger L. Anatomy and humanity: Examining the effects of a short documentary film and first anatomy laboratory experience on medical students. Anat Sci Educ. 2016;9(1):28-39. doi: 10.1002/ase. 1532. [PMID: 25919991] 9. Luis-Alfonso $\mathrm{A}, \mathrm{M} \mathrm{Cl}$, Gloria $\mathrm{C}$. Anxiety and dissection of the human cadaver: An unsolvable relationship? Anat Rec B New Anat. 2004;279B(1):16-23. doi: 10. 1002/ar.b.20022. [PMID: 15278938]

10. Dinsmore CE, Daugherty S, Zeitz HJ. Student responses to the gross anatomy laboratory in a medical curriculum. Clin Anat. 2001;14(3):231-36. doi: 10. 1002/ca.1038. [PMID: 11301472]

11. Plaisant $O$, Courtois R, Toussaint PJ, Mendelsohn GA, John OP, et al. Medical students' attitudes toward the anatomy dissection room in relation to personality. Anat Sci Educ. 2011;4(6):305-10. doi: 10. 1002/ase.251. [PMID: 22065473]

12. Getachew D. Reaction of medical students to experiences in dissection room. Ethiop J Health Sci. 2014;24(4):337-42.

[PMID: 25489198]

13. Sándor I, Birkás E, Györffy Z. The effects of dissection-room experiences and related coping strategies among Hungarian medical students. BMC Med Educ. 2015;15:73. doi: 10.1186/s12909-015-0355-9. [PMID: 25880170]

14. Finkelstein P, Mathers LH. Post-traumatic stress among medical students in the anatomy dissection laboratory. Clin Anat. 1990;3(3):219-26.

15. American Psychiatric Association. Diagnostic and Statistical Manual of Mental Disorders (5th Ed.). Arlington, VA: American Psychiatric Publishing; 2013.

16. Mol SSL, Arntz A, Metsemakers JFM, Dinant G-J, Vilters-van Montfort PAP, Knottnerus JA. Symptoms of post-traumatic stress disorder after non-traumatic events: evidence from an open population study. Br J Psychiatry. 2005;186:494-9. doi: 10.1192/bjp.186.6.494. [PMID: 15928360]

17. PTSD: National Center for PTSD. Accessed at: http://www.ptsd.va.gov/index.asp. Date accessed: May 23, 2016.

18. Bukhbinder A, Schulz PE. Evidence for PTSD as a Systemic Disorder. In: Martin CR, Preedy VR, Patel VB, eds.

Comprehensive Guide to Post-Traumatic Stress Disorders. Springer International Publishing; 2016:21-39.

19. Elhai JD, Miller ME, Ford JD, Biehn TL, Palmieri PA, Frueh BC. Posttraumatic stress disorder in DSM-5: estimates of prevalence and symptom structure in a nonclinical sample of college students. J Anxiety Disord. 2012;26(1):58-64. doi:

10.1016/j.janxdis.2011.08.013. [PMID: 21944437]

20. Miller MW, Wolf EJ, Kilpatrick D, et al. The prevalence and latent structure of proposed DSM- 5 posttraumatic stress disorder symptoms in US national and veteran samples. Psychol Trauma. 2013;5(6):501.

21. Friedman MJ, Resick PA, Bryant RA. Considering PTSD for DSM-5. Depression and Anxiety. 2011;28(9):750-69.

doi:10.1002/da.20767. [PMID: 21910184]

22. American Psychiatric Association. Diagnostic and Statistical Manual of Mental Disorders, (5th Ed.). Washington, DC; 2013.

23. Snelling J, Sahai A, Ellis H. Attitudes of medical and dental students to dissection. Clin Anat. 2003;16(2):165-72. doi:

10.1002/ca.10113. [PMID: 12589673]

24. Bataineh ZM, Hijazi TA, Hijleh MFA. Attitudes and reactions of Jordanian medical students to the dissecting room. Surg Radiol Anat. 2006;28(4):416-21. doi: 10.1007/s00276-006-0101-4. [PMID: 16568219]

25. Bob MH, Popescu CA, Armean MS, Suciu SM, Buzoianu AD. Ethical views, attitudes and reactions of Romanian medical students to the dissecting room. Rev Med Chir Soc Med Nat lasi. 2014;118(4):1078-85. [PMID: 25581973]

26. Arráez-Aybar L-A, Castaño-Collado G, Casado-Morales M-I. Dissection as a modulator of emotional attitudes and reactions of future health professionals. Med Educ. 2008;42(6):563-71. doi: 10.1111/j.1365-2923.2008.03079.x. [PMID: 18452515]

(c) The Internet Journal of Allied Health Sciences and Practice, 2018 
27. Dempster M, Black A, McCorry N, Wilson D. Appraisal and consequences of cadaver dissection. Med Educ Online. 2006;11(16):1-9. doi:10.3402/meo.v11i.4592. [PMID: 28253795]

28. Burriss L, Ayers E, Ginsberg J, Powell DA. Learning and memory impairment in PTSD: relationship to depression. Depress Anxiety. 2008;25(2):149-57. doi:10.1002/da.20291. [PMID: 17352380]

29. Macher D, Paechter M, Papousek I, Ruggeri K. Statistics anxiety, trait anxiety, learning behavior, and academic performance. Eur J Psychol Educ. 2012;27(4):483-98. doi: 10.1007/s10212-011-0090-5.

30. Mancevska S, Pluncevic-Gligoroska J, Dejanova B, Petrovska S, Bozinovska L. Attention and learning in medical students with high anxiety. Neurosci Lett. 2011;500:e46-e47.

31. Schwartz SM, Evans C, Agur AMR. Comparison of physical therapy anatomy performance and anxiety scores in timed and untimed practical tests. Anat Sci Educ. 2015;8(6):518-24. doi:10.1002/ase.1508. [PMID: 25516337]

32. Johnsen GE, Asbjørnsen AE. Consistent impaired verbal memory in PTSD: a meta-analysis. J Affect Disord. 2008;111(1):7482. doi: 10.1016/j.jad.2008.02.007. [PMID: 18377999]

33. Haskell SG, Gordon KS, Mattocks K, Duggal M, Erdos J, et al. Gender differences in rates of depression, PTSD, pain,

obesity, and military sexual trauma among Connecticut War Veterans of Iraq and Afghanistan. J Womens Hlth. 2010;19(2):267-

71. doi: 10.1089/jwh.2008.1262. [PMID: 20109115]

34. Zoladz PR, Diamond DM. Current status on behavioral and biological markers of PTSD: a search for clarity in a conflicting

literature. Neurosci Biobehav Rev. 2013;37(5):860-95. doi:10.1016/j.neubiorev.2013.03.024. [PMID: 23567521]

35. Spinhoven P, Penninx BW, van Hemert AM, de Rooij M, Elzinga BM. Comorbidity of PTSD in anxiety and depressive disorders: prevalence and shared risk factors. Child Abuse Negl. 2014;38(8):1320-30. doi: 10.1016/j.chiabu.2014.01.017. [PMID: 24629482]

36. McCambridge J, Kalaitzaki E, White IR, Khadjesari Z, Murray E, et al. Impact of length or relevance of questionnaires on attrition in online trials: randomized controlled trial. J Med Internet Res. 2011;13(4):e96. doi: 10.2196/jmir.1733. [PMID: 22100793]

37. Hoerger M. Participant dropout as a function of survey length in Internet-mediated university studies: Implications for study design and voluntary participation in psychological research. Cyberpsychol Behav Soc Netw. 2010;13(6):697-700. doi: 10.1089/cyber.2009.0445. [PMID: 21142995]

38. Gray MJ, Litz BT, Hsu JL, Lombardo TW. Psychometric properties of the life events checklist. Assessment. 2004;11(4):330-

41. doi: $10.1177 / 1073191104269954$. [PMID: 15486169]

39. Weathers FW, Blake DD, Schnurr PP, Kaloupek DG. The life events checklist for DSM-5 (LEC-5). Accessed at:

http://www.ptsd.va.gov. Date accessed: June 1, 2016.

40. Ruggiero KJ, Rheingold AA, Resnick HS, Kilpatrick DG, Galea S. Comparison of two widely used PTSD-screening

instruments: Implications for public mental health planning. J Trauma Stress. 2006;19(5):699-707. doi: 10.1002/jts.20141. [PMID: 17075907]

41. Weathers FW, Marx BP, Friedman MJ, Schnurr PP. Posttraumatic Stress Disorder in DSM-5: New Criteria, New Measures, and Implications for Assessment. Psychol Inj Law. 2014;7(2):93-107. doi: 10.1002/jts.21699. [PMID:22729974]

42. Hoge CW, Riviere LA, Wilk JE, Herrell RK, Weathers FW. The prevalence of post-traumatic stress disorder (PTSD) in US combat soldiers: a head-to-head comparison of DSM- 5 versus DSM-IV-TR symptom criteria with the PTSD checklist. The Lancet Psychiatry. 2014/9;1(4):269-77. doi: 10.1016/S2215-0366(14)70235-4. [PMID: 26360860]

43. Blevins CA, Weathers FW, Davis MT, Witte TK, Domino JL. The posttraumatic stress disorder checklist for DSM-5 (PCL-5): development and initial psychometric evaluation. J Trauma Stress. 2015;28(6):489-98. doi: 10.1002/jts.22059. [PMID:26606250] 44. Wortmann JH, Jordan AH, Weathers FW, et al. Psychometric analysis of the PTSD Checklist-5 (PCL-5) among treatmentseeking military service members. Psychol Assess. 2016;28(11):1392-403. doi: 10.1037/pas0000260. [PMID: 26751087] 45. Bovin MJ, Marx BP, Weathers FW, Gallagher MW, Rodriguez P, et al. Psychometric properties of the PTSD checklist for diagnostic and statistical manual of mental disorders-fifth edition (PCL-5) in veterans. Psychol Assess. December 2015. doi:10.1037/pas0000254. [PMID: 26653052]

46. Monson CM, Gradus JL, Young-Xu Y, Schnurr PP, Price JL, Schumm JA. Change in posttraumatic stress disorder symptoms: do clinicians and patients agree? Psychol Assess. 2008;20(2):131-8. doi: 10.1037/1040-3590.20.2.131. [PMID: 18557690]

47. Ashbaugh AR, Houle-Johnson S, Herbert C, El-Hage W, Brunet A. Psychometric validation of the English and French versions of the Posttraumatic Stress Disorder Checklist for DSM-5 (PCL-5). PLoS One. 2016;11(10):e0161645. doi: 10.1371/journal.pone.0161645. [PMID: 27723815]

48. Monson E, Lonergan M, Caron J, Brunet A. Assessing trauma and posttraumatic stress disorder: Single, open-ended question versus list-based inventory. Psychol Assess. 2016;28(8):1001-8. doi: 10.1037/pas0000223. [PMID: 26502204] 49. Mills KL, McFarlane AC, Slade T, Creamer M, Silove D, et al. Assessing the prevalence of trauma exposure in epidemiological surveys. Aust N Z J Psychiatry. 2011;45(5):407-15. doi: 10.3109/00048674.2010.543654. [PMID: 21189046]

(c) The Internet Journal of Allied Health Sciences and Practice, 2018 
50. Peirce JM, Burke CK, Stoller KB, Neufeld KJ, Brooner RK. Assessing traumatic event exposure: comparing the Traumatic Life Events Questionnaire to the Structured Clinical Interview for DSM-IV. Psychol Assess. 2009;21(2):210-8. doi: 10.1037/a0015578. [PMID: 19485675]

51. Bernat JA, Ronfeldt HM, Calhoun KS, Arias I. Prevalence of traumatic events and peritraumatic predictors of posttraumatic stress symptoms in a nonclinical sample of college students. J Trauma Stress. 1998;11(4):645-64. doi: 10.1023/A:1024485130934. [PMID: 9870219]

52. Frazier $\mathrm{P}$, Anders $\mathrm{S}$, Perera $\mathrm{S}$, Tomich $\mathrm{P}$, Tennen $\mathrm{H}$, et al. Traumatic events among undergraduate students: Prevalence and associated symptoms. J Couns Psychol. 2009;56(3):450-60.

53. Chiu KB, deRoon-Cassini TA, Brasel KJ. Factors identifying risk for psychological distress in the civilian trauma population. Acad Emerg Med. 2011;18(11):1156-60. doi: 10.1111/j.1553-2712.2011.01206.x. [PMID: 22044521]

54. Vujanovic AA, Dutcher CD, Berenz EC. Multimodal examination of distress tolerance and posttraumatic stress disorder symptoms in acute-care psychiatric inpatients. J Anxiety Disord. 2017 May;48:45-53. doi:10.1016/j.janxdis.2016.08.005. doi: 10.1016/j.janxdis.2016.08.005. [PMID: 27605231]

55. Hancock D, Williams M, Taylor A. Psychological impact of cadavers and prosections on physiotherapy and occupational therapy students. Aust J Physiother. 1998;44(4):247-55. [PMID: 11676740]

56. Hancock D, Williams M, Taylor A, Dawson B. Impact of cadaver dissection on medical students. NZ J Psychol. 2004;33(1):19-25.

57. Anxiety and Depression Association of American Facts and Statistics [Internet]. [cited 23 May 2018]. Available: https://adaa.org/about-adaa/press-room/facts-statistics\#

58. Dyrbye LN, Thomas MR, Shanafelt TD. Systematic Review of Depression, Anxiety, and Other Indicators of Psychological Distress Among U.S. and Canadian Medical Students. Acad Med. 2006;81(4):354-73. [PMID: 16565188]

59. American College Health Association-National College Health Assessment Data. Accessed at: http://www.achancha.org/reports_ACHA-NCHAllc.html. Date accessed: November 7, 2017.

60. Hojat M, Robeson M, Damjanov I, Veloski JJ, Glaser K, Gonnella JS. Students' psychosocial characteristics as predictors of academic performance in medical school. Acad Med. 1993;68(8):635-7. [PMID:8352877]

61. Vitasari P, Wahab MNA, Othman A, Herawan T, Sinnadurai SK. The Relationship between Study Anxiety and Academic Performance among Engineering Students. Procedia - Social Behavioral Sci. 2010;8:490-7.

62. Seipp B. Anxiety and academic performance: A meta-analysis of findings. Anxiety Research. 1991;4(1):27-41.

63. Watts BV, Schnurr PP, Mayo L, Young-Xu Y, Weeks WB, Friedman MJ. Meta-analysis of the efficacy of treatments for posttraumatic stress disorder. J Clin Psychiatry. 2013;74(6):e541-50. doi: 10.4088/JCP.12r08225. [PMID: 23842024] 64. Bradley R, Greene J, Russ E, Dutra L, Westen D. A multidimensional meta-analysis of psychotherapy for PTSD. Am J Psychiatry. 2005;162(2):214-27. doi: 10.1176/appi.ajp.162.2.214. [PMID: 15677582]

65. Seidler GH, Wagner FE. Comparing the efficacy of EMDR and trauma-focused cognitive-behavioral therapy in the treatment of PTSD: a meta-analytic study. Psychol Med. 2006;36(11):1515-22. doi:10.1017/S0033291706007963. [PMID: 16740177] 66. Baldwin DS, Anderson IM, Nutt DJ, Allgulander C, Bandelow B, et al. Evidence-based pharmacological treatment of anxiety disorders, post-traumatic stress disorder and obsessive-compulsive disorder: a revision of the 2005 guidelines from the British Association for Psychopharmacology. J Psychopharmacol. 2014;28(5):403-39. doi: 10.1177/0269881114525674. [PMID: 24713617]

67. Shalev AY, Peri T, Canetti L, Schreiber S. Predictors of PTSD in injured trauma survivors: a prospective study. Am J Psychiatry. 1996;153(2):219-25. doi:10.1176/ajp.153.2.219. [PMID: 8561202] 


\section{Appendix 1}

\section{PCL-5 Symptoms}

1. Repeated, disturbing, and unwanted memories of the stressful experience

2. Repeated, disturbing dreams of the stressful experience

3. Suddenly feeling or acting as if the stressful experience were actually happening again (as if you were actually back there reliving it)

4. Feeling very upset when something reminded you of the stressful experience

5. Having strong physical reactions when something reminded you of the stressful experience (for example, heart pounding, trouble breathing, sweating)

6. Avoiding memories, thoughts, or feelings related to the stressful experience

7. Avoiding external reminders of the stressful experience (for example, people, places, conversations, activities, objects, or situations)

8. Trouble remembering important parts of the stressful experience

9. Having strong negative beliefs about yourself, other people, or the world (for example, having thoughts such as: I am bad, there is something seriously wrong with me, no one can be trusted, the world is completely dangerous)

10. Blaming yourself or someone else for the stressful experience or what happened after it

11. Having strong negative feelings such as fear, horror, anger, guilt, or shame

12. Loss of interest in activities that you used to enjoy

13. Feeling distant or cut off from other people

14. Trouble experiencing positive feelings (for example, being unable to feel happiness or have loving feelings for people close to you)

15. Irritable behavior, angry outbursts, or acting aggressively

16. Taking too many risks or doing things that could cause you harm

17. Being "superalert" or watchful or on guard

18. Feeling jumpy or easily startled

19. Having difficulty concentrating

20. Trouble falling or staying asleep

Legend Appendix 1: The results of this tool are analyzed using a cutoff score (31 used in this study) are analyzed according to clusters with questions 1-5 representing cluster $B$ items indicating reexperiencing; questions 6 \& 7 representing cluster $C$ items indicating avoidance behaviors; questions 8-14 representing cluster $D$ items indicating negative thoughts and feelings; and questions $15-20$ representing cluster $E$ items indicating arousal and reactivity. 